\title{
Khamir Penghasil Indole-3-Acetic Acid dari Rhizosfer Anggrek Tanah Pecteilis susannae (L.) Rafin
}

\author{
TITI LASMINI ${ }^{1}$, ENDANG SUTARININGSIH SOETARTO ${ }^{1}$ \\ ${ }^{1}$ Jurusan Biologi, Fakultas Biologi, Universitas Gadjah Mada \\ Jl. Teknika Selatan Sekip Utara Yogyakarta 55281 \\ email: lasmini.titi@gmail.com
}

\begin{abstract}
Indole-3-acetic acid (IAA) is a growth hormone produced by plants. Several types of yeast has been reported to produce these hormones, and generally produce IAA in an higher amount than in plants. The purpose of this study is to get the yeast producing indole-3-acetic acid in the rhizosphere soil orchid Pecteilis susannae (L.) Rafin and to test the ability of yeast isolates to form IAA on medium L-tryptophan given as precursors. Yeasts were isolated and tested for their ability to produce IAA in vitro. The results showed that there are four potential yeast isolates that produce IAA which are isolates $\mathrm{K} 2$, U5, A3, and A1. Highest concentration of IAA was produced by A3 isolates grown on a medium containing GPB $200 \mathrm{ug} / \mathrm{ml}$ of L-tryptophan in the amount of $56.262 \mathrm{~g} / \mathrm{ml}$.
\end{abstract}

Keywords: Indole-3-acetic acid, rhizosfer yeast, Pecteilis susannae

\section{PENDAHULUAN}

Pecteilis susannae (L.) Rafin merupakan anggrek tanah yang banyak tumbuh di hutan Wonosadi Gunung Kidul. Anggrek ini umumnya tumbuh di tempat terbuka yang dapat dicapai oleh sinar matahari secara langsung. Vegetasi yang tumbuh di sekitar anggrek ini terutama adalah semak dan rumput. Anggrek $P$. susannae juga memerlukan hormon auksin untuk pertumbuhannya yang diperoleh dari sintesis oleh tumbuhan itu sendiri maupun dari lingkungan. Indole-3-acetic acid (IAA) merupakan salah satu fitohormon golongan auksin alami yang memiliki peran penting dalam pertumbuhan dan perkembangan tanaman seperti pemanjangan dan pembelahan sel, induksi pertumbuhan akar, serta perkembangan bunga dan buah (Kukavica et al., 2007).

Hormon IAA di lingkungan dapat berasal dari mikroorganisme penghasil IAA terutama adalah mikroorganisme yang berasosiasi dengan permukaan akar atau daerah rhizosfer (Manulis et al, 1994). Beberapa jenis khamir telah diketahui mampu menghasilkan IAA, diantaranya adalah spesies khamir Rhodotorula minuta yang berasosiasi dengan cemara dan Williopsis saturnus yang berasosiasi dengan akar jagung (Nassar et al.,
2005) serta Pichia spartinae yang berasosiasi dengan Spartina alterniflora (Nakamura et al., 1991). Beberapa genus kamir seperti Rhodotorula, Cryptococcus, Candida, dan Saccharomyces merupakan komponen utama dalam tanah rhizosfer (Azeredo et al., 1998; Slavikova dan Vadkertiova, 2000; Spencer dan Gorin, 1971). Nassar et al. (2005) menambahkan bahwa pada rhizosfer tanaman juga terdapat khamir seperti Sporobolomyces roseus, Rhodotorula sp., Candida valida, Rhodotorula glutinis, dan Trichosporon asahii. Spesies-spesies yang berasal dari rhizosfer tersebut telah dilaporkan dapat memacu pertumbuhan.

Aktivitas hormon IAA pada tanaman dipengaruhi oleh adanya triptofan. Eksudat akar tanaman adalah sumber triptofan alami bagi mikroorganisme tanah rhizosfer, yang dapat meningkatkan biosintesis auksin pada daerah rhizosfer (Kamilova et al., 2006). Pemberian L-triptofan ke dalam kultur in vitro bakteri, fungi, maupun khamir penghasil IAA.

\section{METODE}

Isolasi khamir dari tanah rhizosfer anggrek $\boldsymbol{P}$. susannae. Isolasi khamir diawali dengan membuat seri pengenceran sampel tanah rhizosfer dari $10^{-1}$ sampai $10^{-5}$ menggunakan akuades steril. Masing-masing 
seri pengenceran diinokulasikan $0,1 \mathrm{ml}$ pada media Yeast Malt Agar (YMA) dengan metode pour plate, diinkubasikan pada suhu ruang selama 5 hari. Medium YMA yang digunakan mengandung $1 \mathrm{mg} / \mathrm{ml}$ kloramfenikol untuk mencegah pertumbuhan bakteri. Kolonikoloni yang tumbuh terpisah kemudian diambil dan dimurnikan pada medium YMA baru dengan cara goresan. Koloni yang tumbuh terpisah merupakan koloni tunggal, dipindahkan ke medium YMA baru, sebagai kultur murni yang diuji lebih lanjut.

Uji kemampuan tumbuh isolat khamir pada medium cair. Seluruh isolat khamir yang diperoleh di tumbuhan pada medium cair Glucose Peptone Broth (GPB). Kultur khamir (48-72 jam) ditumbuhkan ke dalam $5 \mathrm{ml}$ medium GPB, diinkubasikan pada suhu kamar selama 48 jam. Kultur cair tersebut diamati pertumbuhannya secara spektrofotometri $\left(\mathrm{OD}_{530} \mathrm{~nm}\right)$. Setelah mencapai $\mathrm{OD}_{600} \mathrm{~nm}=0,6$ kultur tersebut digunakan sebagai inokulum. Masing-masing kultur cair khamir tersebut diambil $2 \mathrm{ml}$ dan diinokulasikan ke dalam 20 $\mathrm{ml}$ medium GPB steril yang mengandung 200 $\mu \mathrm{g} / \mathrm{ml}$ L-Triptofan di dalam erlenmeyer 100 $\mathrm{ml}$, diinkubasikan pada shaker incubator (120 rpm, $30^{\circ} \mathrm{C}$ ) selama 96 jam. Erlenmeyer yang berisi medium steril tanpa inokulum digunakan sebagai kontrol. Secara kualitatif kandungan IAA dideteksi berdasarkan perubahan warna yaitu dengan menambahkan reagen Salkowsky ke dalam supernatan kultur khamir. Kultur khamir disentrifugasi (10.000 rpm, 30 menit). Supernatan dipisahkan kemudian diambil $1 \mathrm{ml}$, ditambah dengan $1 \mathrm{ml}$ reagen Salkowsky, dibiarkan selama 30 menit sampai terjadi perubahan warna menjadi pink hingga merah (Shrivastava et al, 2008), diukur berdasarkan absorbansi spektrofotometri ( $\mathrm{A}_{530}$ $\mathrm{nm})$. Nilai tersebut dibandingkan dengan hasil pembacaan larutan standar menggunakan IAA sintetik dengan konsentrasi 1 sampai $10 \mu \mathrm{g} / \mathrm{ml}$ IAA (Nassar et al., 2005; Shrivastava et al., 2008).

Percobaan produksi IAA oleh isolat khamir terpilih. Masing-masing inokulum isolat khamir terpilih diambil $2 \mathrm{ml}$, diinokulasikan secara aseptis ke dalam $20 \mathrm{ml}$ medium GPB dan SBM baru tanpa penambahan L-triptofan dan medium yang telah dimodifikasi dengan penambahan 200 $\mu \mathrm{g} / \mathrm{ml}$ L-triptofan di dalam erlenmeyer $100 \mathrm{ml}$. Medium steril tanpa inokulum digunakan sebagai kontrol. Kultur diinkubasikan pada shaker incubator $\left(120 \mathrm{rpm}, 30^{\circ} \mathrm{C}\right)$ selama 96 jam. Pertumbuhan khamir dipantau dengan mengukur biomassa sel $\left(\mathrm{OD}_{600} \mathrm{~nm}\right)$ tiap interval waktu tertentu selama 96 jam. Hasil pengukuran $\left(\mathrm{OD}_{600} \mathrm{~nm}\right)$ tersebut digunakan untuk menentukan jumlah sel. Jumlah sel selama pengukuran pertumbuhan ditentukan dengan memasukkan nilai absorban $\left(\mathrm{OD}_{600}\right.$ $\mathrm{nm})$ ke kurva standar pertumbuhan khamir. Konsentrasi IAA ditentukan secara kolorimetri pada spektrofotometri (OD530 $\mathrm{nm})$ dengan menambahkan reagen Salkowky.

Ekstraksi dan identifikasi senyawa IAA dari kultur isolat khamir terpilih. Senyawa yang dihasilkan di dalam kultur isolat khamir terpilih diperoleh melalui ekstraksi. Supernatan yang diperoleh dari hasil sentrifugasi (10.000 rpm, 30 menit) $20 \mathrm{ml}$ kultur cair khamir terpilih diekstraksi dua kali menggunakan etil asetat dengan perbandingan 1:2 (v/v) pada cawan porselen. Fraksi etil asetat dievaporasi hingga diperoleh fase padatan. Fase padatan (ekstrak) dilarutkan dalam $2 \mathrm{ml}$ methanol, diambil dengan pipa kapiler $(10 \mu \mathrm{l})$ kemudian ditotolkan pada lempeng silika gel (silika gel $\mathrm{Gf}_{254}$, ketebalan $0,25 \mathrm{~mm}$ ) berukuran $5 \times 10 \mathrm{~cm}$. Larutan IAA sintetik $(200 \mu \mathrm{g} / \mathrm{ml})$ ditotolkan pada lempeng silika gel sebagai pembanding. Totolan antar sampel pada lempeng silika gel dibuat dengan jarak $\pm 1 \mathrm{~cm}$. Lempeng tersebut dimasukkan ke dalam chamber yang tertutup rapat berisi eluen etil asetat: kloroform: formic acid dengan perbandingan 55:35:10 (v/v/v). Spot yang terbentuk kemudian diamati dibawah sinar UV $\lambda 254$ dan $\lambda 365$ (Ahmad et al., 2005).

\section{HASIL}

Pada penelitian ini, sebanyak 29 isolat khamir berhasil diisolasi. Hanya empat isolat khamir mampu menghasilkan IAA yang lebih intens secara visualisasi yaitu isolat $\mathrm{K} 2, \mathrm{U} 5$, A3, dan A1. Pada saat dilakukan pengukuran dengan spektrofotometri keempat isolat tersebut menghasilkan IAA lebih dari \pm 15 
$\mu \mathrm{g} / \mathrm{ml}$. Isolat-isolat tersebut dipilih untuk percobaan produksi IAA. Isolat khamir terpilih mampu menghasilkan IAA baik pada medium tanpa L-triptofan maupun pada medium dengan penambahan $200 \mu \mathrm{g} / \mathrm{ml}$ L-triptofan. Produksi IAA pada medium tanpa L-triptofan lebih rendah dari medium yang ditambah Ltriptofan. Pada medium tanpa L-triptofan, isolat $\mathrm{K} 2$ mampu menghasilkan konsentrasi IAA tertinggi yaitu sebesar $11,048 \mu \mathrm{g} / \mathrm{ml}$ pada medium GPB, dan 2,428 $\mu \mathrm{g} / \mathrm{ml}$ pada medium SBM.
Pada medium dengan penambahan Ltriptofan sebesar $200 \mu \mathrm{g} / \mathrm{ml}$, produksi IAA tertinggi pada medium GPB diperoleh dari isolat A3 yaitu sebesar 56,262 $\mu \mathrm{g} / \mathrm{ml}$, sedangkan pada medium SBM diperoleh dari isolat U5 yaitu sebesar 5,809 $\mu \mathrm{g} / \mathrm{ml}$. Produksi IAA keempat isolat terpilih memiliki pola yang sama dengan pola pertumbuhan sel. Produksi IAA semakin meningkat dengan meningkatnya pertumbuhan dan jumlahnya semakin menurun seiring dengan semakin menurunnya pertumbuhan (Gambar 1).

Tabel 1. Produksi IAA isolat khamir terpilih pada medium glucose-peptone-broth (GPB) dan salt basalmedium (SBM) tanpa dan dengan penambahan $200 \mu \mathrm{g} / \mathrm{ml} \mathrm{L}$-triptofan

\begin{tabular}{|c|c|c|c|c|c|c|}
\hline \multirow{2}{*}{ Media } & \multirow{2}{*}{ Kode Isolat } & \multicolumn{5}{|c|}{ Konsentrasi IAA $(\mu \mathrm{g} / \mathrm{ml}) / \mathrm{Jam}$} \\
\hline & & 0 & 24 & 48 & 72 & 96 \\
\hline \multirow[t]{5}{*}{ GPB0 } & Kontrol & 6,143 & 6,214 & 6,143 & 5,929 & 5,929 \\
\hline & $\mathrm{K} 2$ & 6,619 & 8,452 & $11,048^{*}$ & 9,881 & 9,119 \\
\hline & U5 & 6,619 & $10,69^{*}$ & 10,238 & 9,809 & 7,714 \\
\hline & A3 & 6,476 & $10,595^{*}$ & 9,381 & 7,405 & 6,762 \\
\hline & A1 & 6,286 & 9,333 & 9,619 & $9,738^{*}$ & 8,524 \\
\hline \multirow[t]{5}{*}{ GPB200 } & Kontrol & 7,857 & 8,214 & 7,857 & 7,643 & 7,643 \\
\hline & $\mathrm{K} 2$ & 8,022 & 30,405 & $31,191 *$ & 29,952 & 21 \\
\hline & U5 & 7,952 & 28,452 & $51,524^{*}$ & 45,286 & 21,834 \\
\hline & A3 & 8,143 & 35,31 & $56,262 *$ & 48,833 & 27,643 \\
\hline & A1 & 8,095 & 12,452 & $12,905^{*}$ & 13,286 & 11,69 \\
\hline \multirow[t]{5}{*}{ SBM0 } & Kontrol & 0,929 & 1 & 1 & 0,929 & 0,929 \\
\hline & $\mathrm{K} 2$ & 1,119 & $2,428^{*}$ & 1,714 & 1,262 & 1,19 \\
\hline & U5 & 1,095 & 1,119 & $1,167^{*}$ & 1,072 & 1,024 \\
\hline & A3 & 1,047 & $1,119^{*}$ & 1,048 & 0,976 & 0,953 \\
\hline & A1 & 1,143 & 1,238 & $1,452 *$ & 1,119 & 0,929 \\
\hline \multirow[t]{5}{*}{ SBM200 } & Kontrol & 2 & 2 & 2,071 & 1,643 & 1,643 \\
\hline & K2 & 2,095 & 2,524 & $2,789^{*}$ & 2,19 & 1,976 \\
\hline & U5 & 2,166 & 3,524 & 5,095 & 5,048 & $5,809^{*}$ \\
\hline & $\mathrm{A} 3$ & 1,976 & 2,072 & $2,619^{*}$ & 2,119 & 1,976 \\
\hline & A1 & 2,095 & 2,191 & 2,262 & $2,619^{*}$ & 2,024 \\
\hline
\end{tabular}

Keterangan: Nilai diperoleh dari rata-rata tiga ulangan; GPB0 : medium GPB tanpa L-triptofan; GPB200: medium GPB mengandung $200 \mu \mathrm{g} / \mathrm{ml}$ L-triptofan; SBM0: medium SBM tanpa L-triptofan; SBM200: medium SBM mengandung $200 \mu \mathrm{g} / \mathrm{ml}$ L-triptofan; * produksi IAA tertinggi yang dicapai pada kultur isolat khamir. 
Isolat K2

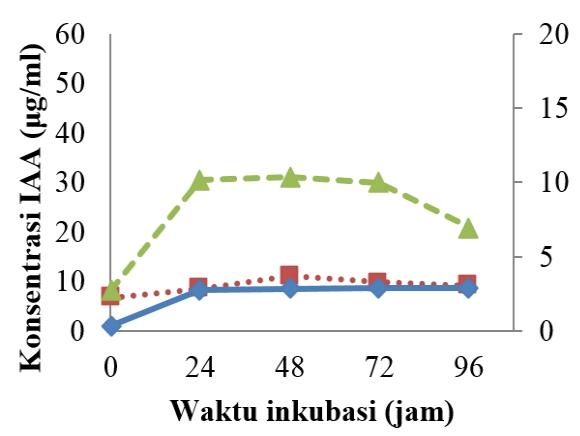

Isolat A3

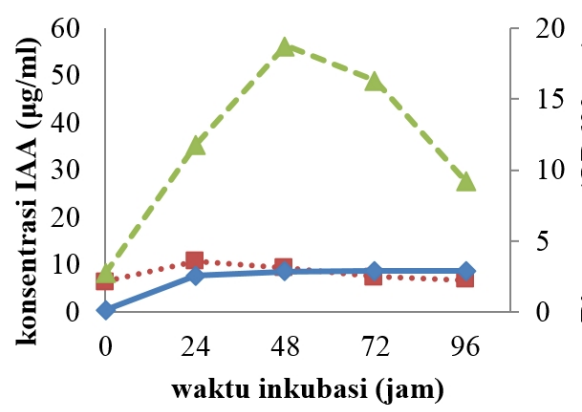

Isolat U5

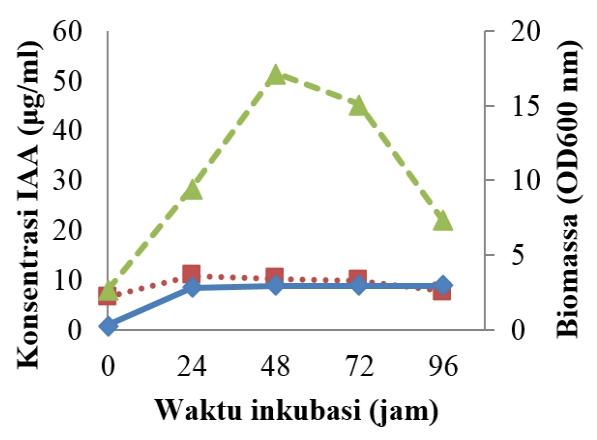

Isolat A1

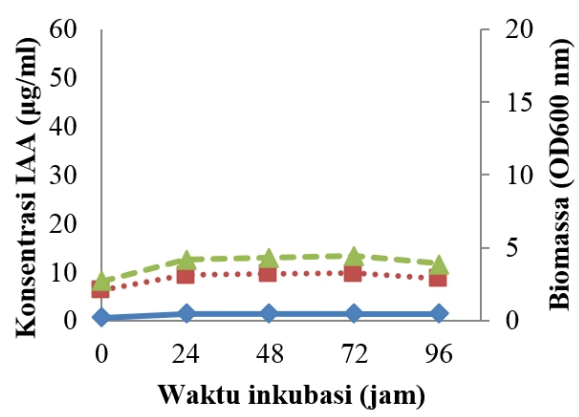

Gambar 1. Kemampuan isolat terpilih untuk produksi IAA $\left(\mathrm{OD}_{530} \mathrm{~nm}\right)$ pada medium GPB. Simbol-simbol: $\diamond$ pertumbuhan sel; $\square$ produksi IAA pada medium tanpa L-triptofan; $\Delta$ produksi IAA pada medium dengan penambahan $200 \mu \mathrm{g} / \mathrm{ml} \mathrm{L}$ triptofan.

\section{Isolat K2}

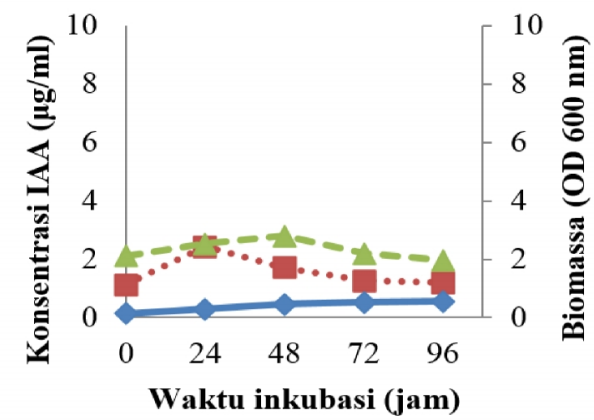

Isolat A3

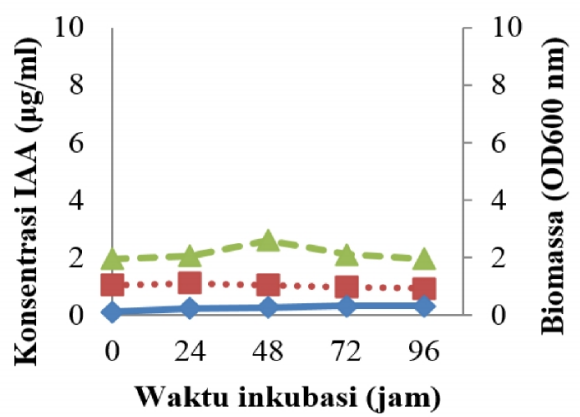

Isolat U5

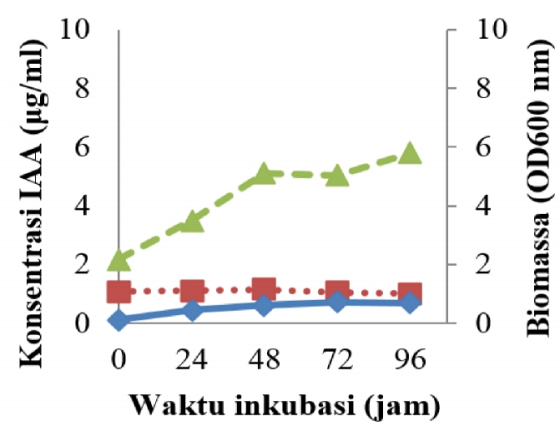

Isolat A1

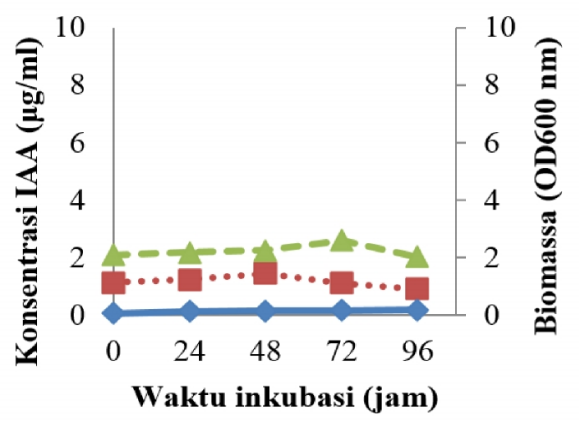

Gambar 2. Kemampuan isolat terpilih untuk produksi IAA $\left(\mathrm{OD}_{530} \mathrm{~nm}\right)$ pada medium SBM. Simbol-simbol: $\diamond$ pertumbuhan sel; $\square$ produksi IAA pada medium tanpa L-triptofan; $\Delta$ produksi IAA pada medium dengan penambahan $200 \mu \mathrm{g} / \mathrm{ml}$ L-triptofan. 
Pada medium GPB produksi mencapai tertinggi dalam waktu 48 jam. Dalam rentang waktu tersebut sel khamir telah memasuki fase akhir logaritmik dan memasuki fase stasioner. Seiring dengan bertambahnya waktu kandungan IAA dalam media semakin menurun.

Produksi IAA keempat isolat terpilih pada medium SBM juga mengikuti pertumbuhan sel. Konsentrasi IAA tertinggi dihasilkan pada saat sel memasuki akhir fase logaritmik atau fase awal stasioner (gambar 2).

Pada medium SBM pertumbuhan sel lebih lambat sehingga IAA yang dihasilkan juga lebih sedikit dibandingkan GPB. Produksi IAA pada medium ini mencapai puncak dalam waktu yang berbeda-beda pada setiap isolat terpilih. Isolat K2 dan A3 mencapai produksi tertinggi pada jam ke 48, isolat U5 pada jam ke 96, dan isolat A1 pada jam ke 72.

Produksi IAA dipengaruhi oleh kecepatan tumbuh sel khamir. Semakin cepat sel membelah produksi IAA semakin tinggi, semakin lambat sel membelah maka jumlah IAA yang dihasilkan juga semakin rendah. Berdasarkan pengukuran kecepatan pertumbuhan, menunjukkan bahwa isolat A3 memiliki waktu generasi tercepat, sedangkan isolat A1 memiliki waktu tumbuh paling lambat sehingga menyebabkan rendahnya produksi IAA pada isolat A1.

Dari hasil KLT diketahui bahwa IAA sintetik memiliki nilai $R f$ 0,69. Hasil kromatografi terhadap senyawa yang dihasilkan oleh keempat isolat khamir uji pada pelat silika menunjukkan bahwa pada kultur isolat U5 dan A3 terdapat senyawa yang identik dengan IAA yaitu dengan nilai $R f 0,69$.

\section{PEMBAHASAN}

Kemampuan khamir dalam menghasilkan IAA distimulasi dengan penambahan Ltriptofan. Asam amino triptofan dimetabolisme oleh khamir melalui fisiologi lintasan metabolik dikonversikan menjadi IAA (Zhao, 2010). Dengan kata lain, L-triptofan mengaktifasi gen yang bertanggung jawab untuk sintesis enzim triptofan monooksigenase, IAM hidrolase, indol piruvat dekarboksilase dan IAAld dehidrogenase
(Spaepen dan Vanderleyden, 2007; Zhao, 2010), enzim-enzim tersebut berperan mengkonversi L-triptofan menjadi IAA.

Pada medium GPB isolat A3 menghasilkan IAA paling tinggi. Tingginya produksi IAA pada medium GPB dibanding pada medium SBM disebabkan medium GPB tidak mengandung substansi yang dapat menghambat sintesis IAA secara langsung maupun tidak langsung seperti ammonium (Tsavkelova et al., 2005). Medium GPB mengandung cukup nutien, sumber karbon dan nitrogen yang diperlukan untuk mendukung pertumbuhan dan perkembangan optimal kultur khamir.

Rendahnya produksi IAA pada medium SBM disebabkan adanya ammonium sulfat dalam medium kultur. Menurut Tsavkelova et al. (2005) ion ammonium dapat menghambat sintesis IAA. IAA dapat tereduksi dengan adanya suplai nitrogen eksogenous seperti nitrat, ammonium, urea dan glisin. Nitrat dapat mempengaruhi pembentukan IAA dengan dikonversi menjadi nitrit yang dapat memecah IAA secara katalitik (Frankenberger dan Arshad, 1995). Salt Basal Medium merupakan medium sintetik yang hanya terdiri dari garam dan mineral sehingga tidak memiliki cukup nutrien yang dibutuhkan untuk pertumbuhan sel dan perkembangan optimal kultur khamir sehingga mempengaruhi biosintesis IAA. Produksi IAA dalam kultur mikrobia juga dapat dipengaruhi oleh temperatur dan aerasi yang juga merupakan faktor pertumbuhan bagi mikroba (Simat et al., 2004).

Produksi IAA keempat isolat terpilih memiliki pola yang sama dengan pola pertumbuhan sel. Produksi IAA semakin meningkat dengan meningkatnya pertumbuhan dan jumlahnya semakin menurun seiring dengan semakin menurunnya pertumbuhan. Kecepatan sel khamir dalam membelah ini dipengaruhi oleh medium pertumbuhan dan kondisi lingkungannya seperti temperatur. Faktor-faktor pertumbuhan yang dibutuhkan untuk pertumbuhan dapat meliputi vitamin, purin dan pirimidin, asam amino, asam lemak, sterol (terutama ergosterol), biotin dan panthothenic acid (Simat et al., 2004). 
Konsentrasi IAA tertinggi dihasilkan pada saat sel memasuki akhir fase logaritmik atau fase awal stasioner (48 jam). Produksi IAA tertinggi dicapai pada fase ini karena pada fase ini enzim-enzim yang diperlukan untuk sintesis IAA berada dalam jumlah yang banyak sehingga produksi IAA juga tinggi (Atlas, 1997; Kresnawaty et al., 2008).

Pada waktu inkubasi 72 jam baik pada medium GPB maupun SBM, sel-sel khamir telah memasuki akhir fase stasioner atau memasuki fase kematian. Hal ini ditandai dengan tidak adanya penambahan jumlah sel sampai pada waktu inkubasi 96 jam. Pada rentang waktu tersebut produksi IAA mengalami penurunan. Penurunan produksi IAA mengindikasikan adanya proses degradasi IAA oleh enzim yang dilepaskan oleh sel-sel khamir seperti oksidase dan peroksidase. Degradasi IAA dapat terjadi melalui mekanisme oksidasi menghasilkan dioxindole3-acetic acid (Rachmawati et al., 2009). Dioxindole-3-acetic acid ini kemudian dioksidasi menjadi isatin yang pada kondisi asam akan mengalami hidrolisis menjadi anthranilic acid (Jensen et al., 1995).

Jika dibandingkan antara pertumbuhan sel khamir pada medium GPB dan SBM, pertumbuhan sel khamir pada medium SBM cenderung lebih lambat. Lambatnya pertumbuhan sel pada medium SBM menjadi salah satu faktor yang menyebabkan rendahnya produksi IAA. Lambatnya pertumbuhan sel khamir dalam medium SBM kemungkinan disebabkan karena terbatasnya sumber nutrien dalam medium tersebut.

\section{DAFTAR PUSTAKA}

Ahmad F, Ahmad I, and Khan MS. 2005. Indole Acetic Acid Production by The Indigenous Isolates of Azotobacter and Fluorescent Pseudomonas in The Presence and Absence of Tryptophan. Turk Journal of Biology. vol 29: 29-34.

Atlas RM. 1997. Principle of Microbiology. London: Brown Publishers.

Azeredo LAI, Gomes EAT, Hagler LCM, and Haggler AN. 1998. Yeast Communities Associated With Sugarcane in Compos,
Rio de Janeiro, Brazil. International Microbiology. vol 1: 205-208.

Frankenberger WT and Arshad M. 1995. Phytohormones in Soil: Microbial Production and Function. New York: Marcel Dekker, Inc.

Jensen JB, Egsgaard H, van Onckelen H, and Jochimsen BU. 1995. Catabolism of Indole-3-Acetic Acid and 4- and 5Chloroindole-3-Acetic Acid in Bradyrhizobium japonicum. Journal of Bacteriology. vol 177 (20):5762-5766.

Kamilova F, Kravchenko LV, Shaposhnikov AI, Azarova T, Makarova N, and Lugtenberg B. 2006. Organic Acids, Sugars, and L-tryptophane in Exudates of Vegetables Growing on Stonewool and Their Effects on Activities on Rhizosphere Bacteria. Molecular plant microbe interaction. vol 1:1.

Kresnawaty I, Andanawarih S, Suharyanto, dan Tripanji. 2008. Optimasi dan Pemurnian IAA yang Dihasilkan Rhizobium sp. Dalam Medium Serum Lateks Dengan Suplementasi Triptofan dari Pupuk Kandang. Menara Perkebunan. vol 1:1.

Kukavica B, Mitrovic A, Mojovic M, and Jovanovic SV. 2007. Effect of indole 3acetic acid on Pea Root Growth, Peroxidase Profiles and Hydroxyl Radical Formation. Arc.Biol.Sci. vol 59(4):319126.

Manulis S, Shafrir H, Epstein E, Lichter A, and Barash I. 1994. Biosynthesis of Indole 3Acetic Acid via The Indole 3-Acetamide Pathway in Streptomyces spp. Microbiology. vol 140:1045-1050.

Nakamura T, Murakami T, Saotome M, Tomita K, Kitsuwa $\mathrm{T}$ and Meyers SP. 1991. Identification of Indole 3-Acetic Acid in Pichia spartinae an ascosporogenous Yeast from Spartina alterniflora Marshland Environments. Mycologia. vol 83(5):662-664.

Nassar AH, El-tarabily KA, and Sivasithamparam K. 2005. Promotion of Plant Growth by An Auxin-Producing Isolate of The Yeast Williopsis saturnus 
Endophytic in Mayze (Zea mays L.) Roots. Biology fertile soil. vol 42:97-106.

Rachmawati D, Nasir M, Sudjino, Dewi K. 2009. Fisiologi Tumbuhan. Yogyakarta: Fakultas Biologi Universitas Gadjah Mada.

Shrivastava S, D'souja SF and Desai PD. 2008. Production of Indole 3-Acetic Acid by Immobilized Actinomycetes (Kitasatospora sp.) for Soil Application. Current Science. vol 94 (12): 1595-1565.

Simat TJ, Hoenicke K, Gessner M, and Christoph N. 2004. Metabolism of Tryptophan and Indole-3-Acetic Acid Formation During Vinification and Its Influence on The Formation of 2Aminoacetophenone. Mitteilungen Klosterneuburg. vol 55:43-55.
Slavikova E, and Vadkertiova R. 2000. The Occurrence of Yeast in The Forest Soils. Journal Basics of Microbiology. [Abstract].

Spaepen S, and Vanderleyden J. 2010. Auxin and Plant-Microbe Interaction. Belgium: Cold Spring Harbor Laboratory Press.

Spencer JFT, and Gorin PAJ. 1971. Yeasts Isolated From Soil of Citrus Orchards and Citrus Waste Disposal Areas in California and Florida. Canadian Journal of Microbiology. [Abstract].

Tsavkelova EA, Cherdyntseva TA, and Netrusov AI. 2005. Auxin Production by Bacteria Associated with Orchid Roots. Microbiology. vol 74(1): 46-53.

Zhao Y. 2010. Auxin Biosynthesis and Its Role in Plant Development. Annual Review Plant Biology. vol 61: 49-64. 